\title{
Penerapan Metode Principal Component Analysis (PCA) Terhadap Faktor- faktor yang Mempengaruhi Lamanya Penyelesaian Skripsi Mahasiswa Program Studi Pendidikan Matematika FKIP UNDANA
}

\author{
Magdalena Wangge \\ 1,2 Program Studi Pendidikan Matematika, Fakultas Keguruan dan Ilmu Pendidikan, Universitas Nusa Cendana, \\ J1. Adisucipto, Kupang, 85228, NTT, Indonesia \\ Email: magdalena.wangge@ staf.undana.ac.id
}

\begin{abstract}
Completion of a thesis is a correct procedure based on the knowledge learned in the allowed time. The thesis's length of completion is more than one year experienced by students in Mathematics Education Program at Nusa Cendana University due to several factors. This study aimed to determine the dominant factors that affect the thesis completion of students Mathematics education Program at Nusa Cendana University. The research method used is quantitative research. On Mathematics Education Program of Nusa Cendana University, Kupang January until February 2020, conducted the research. The primary data obtained by distributing questionnaires to students of Mathematics Education FKIP Undana was numbering 50 peoples. Secondary data obtained from the Laboratory of Mathematics Education form data of mathematics student graduates. In this study, Principal Component Analysis (PCA) is used to reduce 13 variables to get 10 variables, that the quality of thesis guidance, the availability of learning resources, motivation to graduate on time, mentoring style of lecturer, attitude and interaction with the supervisor, students activities, the atmosphere of shelter, peer environment, divide the time, healthy, lack of parents attention, emotional intelligence, and the ability to write scientific papers so that there are four main components called thesis writing supporting factors, motivational factors graduate on time, timesharing factors, and writing ability factors. In conclusion, the four main components can be considered by students to arrange the length of completion of the thesis so that it is expected to be completed on time be considered.
\end{abstract}

Keywords: Principal Component Analysis, Thesis, Thesis Completion Factor

\begin{abstract}
Abstrak
Penyelesaian skripsi adalah suatu proses penyelesaian sebuah hasil karya tulis ilmiah sesuai prosedur yang benar berdasarkan ilmu yang telah dipelajari dalam waktu yang telah ditentukan. Lamanya penyelesaian skripsi lebih dari 1 tahun yang dialami oleh mahasiswa di Pendidikan Matematika FKIP Undana, disebabkan adanya beberapa faktor yang mempengaruhi. Tujuan dari penelitian ini adalah untuk mengetahui faktor-faktor dominan yang mempengaruhi penyelesaian skripsi mahasiswa Program Studi Pendidikan Matematika Undana. Metode penelitian yang digunakan adalah penelitian kuantitatif. Penelitian ini dilakukan pada Program Studi Pendidikan Matematika Universitas Nusa Cendana Kupang pada bulan Januari-Februari 2020. Data yang digunakan adalah data primer yang diperoleh dengan menyebarkan angket kepada alumni mahasiswa Jurusan/Prodi Pendidikan Matematika yang berjumlah 50 orang dan data sekunder diperoleh dari Laboratorium berupa data wisudawan mahasiswa matematika. Dalam penelitian ini, Principal Component Analysis (PCA) digunakan untuk mereduksi 13 variabel hingga diperoleh 10 variabel yaitu kualitas bimbingan skripsi, ketersediaan sumber belajar terhadap skripsi, motivasi lulus tepat waktu, gaya bimbingan dosen, sikap dan interaksi dengan dosen pembimbing, kegiatan kemahasiswaan, lingkungan teman sebaya, membagi waktu, perhatian orang tua dan kemampuan menulis karya ilmiah sehingga diperoleh 4 komponen utama yang disebut faktor pendukung penulisan skripsi, faktor motivasi lulus tepat waktu, faktor membagi waktu dan faktor kemampuan menulis. Kesimpulannya 4 komponen utama tersebut dapat menjadi bahan pertimbangan mahasiswa untuk dapat mengatur lama penyelesaian skripsi, sehingga diharapkan dapat selesai tepat waktu.
\end{abstract}

Kata kunci: Principal Component Analysis, Skripsi, Faktor Penyelesaian Skripsi

Copyright (c) 2021 Magdalena Wangge

प Corresponding author: Magdalena Wangge

Email Address: magdalena.wangge@ @staf.undana.ac.id (Jl. Adisucipto, Kupang, 85228, NTT)

Received 22 March 2021, Accepted 09 April 2021, Published 12 April 2021

\section{PENDAHULUAN}

Skripsi merupakan suatu karya ilmiah yang diwajibkan sebagai bagian dari persyaratan pendidikan akademis di perguruan tinggi. Skripsi yang dibuat oleh mahasiswa merupakan laporan 
Penerapan Metode Principal Component Analysis (PCA) Terhadap Faktor-faktor yang Mempengaruhi Lamanya Penyelesaian Skripsi Mahasiswa Program Studi Pendidikan Matematika FKIP UNDANA, Magdalena Wangge

penelitian yang dilakukan terhadap suatu permasalahan dalam bidang ilmu tertentu berdasarkan teoriteori dan disiplin ilmu yang sesuai disetiap perguruan tinggi (Rismen, 2015). Penyelesaian sebuah skripsi mahasiswa harus didasari dengan ilmu statistika elementer, evaluasi pembelajaran, strategi pembelajaran dan metodologi penelitian serta ilmu lainnya sesuai jurusan yang dijalani. Pada umumnya, proses bimbingan mahasiswa dibimbing oleh dua orang pembimbing. Kemudian dilanjutkan dengan ujian proposal, ujian hasil dan ujian skripsi oleh seorang penguji bersama dua pembimbing sebelumnya.

Proses penyelesaian skripsi yang efektif adalah 6 bulan atau 1 semester. Dalam proses belajar hingga penyelesaian skripsi, tentulah tidak akan selamanya berjalan dengan mulus, pasti adakalanya mahasiswa mengalami hambatan dalam penyelesaiannya. Hambatan yang dialami mahasiswa seperti masalah kesehatan, kurangnya pengetahuan cara menulis karya ilmiah, kurangnya motivasi dalam diri maupun dari orang lain, cara bergaul yang salah serta kendala saat konsultasi dengan dosen. Banyak peneliti yang sudah mengkaji terkait masalah penyelesaian skripsi ini (Adelina, 2018; Annisa, 2012; Broto, 2016; Hadiono, 2012; Hariyadi et al., 2017; Hartato \& Aisyah, 2011; Kurniati, 2010; Pratiwi \& Roosyanti, 2019; Sulasteri et al., 2019). Pengalaman seperti ini juga dialami oleh mahasiswa di Jurusan Pendidikan Matematika, yang berada di Universitas Nusa Cendana.

Dari hasil wawancara sementara yang diperoleh dari 35 mahasiswa, didapati informasi bahwa beberapa hambatan yang dialami mahasiswa pendidikan matematika undana dalam menyelesaikan tugas akhir skripsi mereka diantaranya adalah masalah kesehatan sebanyak 4 mahasiswa atau sebesar 11\%, kurangnya pengetahuan cara menulis karya ilmiah sebanyak 6 mahasiswa atau sebesar 17\%, kurangnya motivasi dalam diri maupun orang lain sebanyak 8 mahasiswa atau sebesar $23 \%$, cara bergaul yang salah sebanyak 7 mahasiswa atau sebesar $20 \%$ dan kendala saat konsultasi dengan dosen sebanyak 10 mahasiswa atau sebesar $29 \%$.

Peneliti mengambil data tanggal penerimaan judul skripsi mahasiswa, data jadwal ujian porposal dan data jadwal ujian skripsi mahasiswa Pendidikan Matematika dengan melakukan wawancara pada bagian administrasi jurusan. Data yang dikumpulkan selama 4 tahun yaitu dari bulan Januari 2017 sampai Oktober 2020. Hasil wawancara peneliti pada tanggal 24 Januari 2020 memperoleh lamanya mahasiswa Pendidikan Matematika menyelesaikan skripsi.

Tabel 1. Data Lama Penyelesaian Skripsi 5 tahun terakhir

\begin{tabular}{|c|c|c|}
\hline Lama Penyelesaian Skripsi & Jumlah (mahasiswa) & \multirow{2}{*}{ Total } \\
\hline < 6 bulan & 8 & \multirow{2}{*}{ bulan $=\mathbf{1 3}$} \\
\hline 6 bulan & 5 & \multirow{3}{*}{$>$} \\
\hline 7 bulan & 7 & \\
\hline 8 bulan & 8 & \\
\hline 9 bulan & 6 & \\
\hline 10 bulan & 19 & \\
\hline 11 bulan & 3 & \\
\hline 12 bulan & 10 & \\
\hline$>1$ tahun & 17 & \\
\hline Total & $\mathbf{8 3}$ & \\
\hline
\end{tabular}

Sumber: data primer (sampai bulan september 2020) 
Banyak mahasiswa dari Jurusan Pendidikan Matematika yang mengalami hambatan dalam penyelesaian skripsi. Berdasarkan data yang diperoleh, lebih banyak mahasiswa yang menyelesaikan skripsi selama 7-12 bulan bahkan lebih. Lamanya proses dalam penyelesaian skripsi dapat menunda mahasiswa-mahasiswi diwisudakan serta mendapat pekerjaan. Ini juga dapat berpengaruh pada akreditasi jurusan. Hal ini disebabkan oleh banyak faktor. Faktor-faktor yang memengaruhi penyelesaian skripsi mahasiswa Pendidikan Matematika merupakan salah satu hal yang cukup penting untuk digali, untuk itu perlu diungkap faktor-faktor apa saja yang memengaruhi penyelesaian mahasiswa. Sehingga, dalam penelitian ini akan dianalisis berbagai faktor yang memengaruhi penyelesaian skripsi mahasiswa Pendidikan Matematika Undana.

Karena terdapat banyak faktor yang memengaruhi penyelesaian skripsi mahasiswa maka pada penelitian ini, akan dicari faktor-faktor yang menjadi faktor utamanya dengan menggunakan metode Principal Componen Analisys (PCA) dan dari faktor utama yang diperoleh akan diregresikan atau dimodelkan dengan menggunakan metode regresi berganda. Banyak penelitian yang sudah dilakukan dengan metode PCA (Elfira, 2014; Fitrianingsiha \& Sugiyartob, 2018; Hadi, 2015; Hermawan, 2019; Juaeni, 2014; Kurniawan, 2008; Kustian, 2016; Mariana, 2013; Maulana, 2018; Nasution, 2019; Noya van Delsen et al., 2017; Qomari, 1970; Radiarta, I Nyoman, Hasnawi, 2013; Saepurohman \& Putro, 2019; Syakhala et al., 2015; Wirayanti et al., 2014; Zein et al., 2019).

Principal Componen Analisys ( $P C A$ ) adalah suatu teknik statistik multivariat yang secara linear mengubah bentuk sekumpulan variabel asli menjadi kumpulan variabel yang lebih kecil yang tidak berkorelasi yang dapat mewakili informasi dari kumpulan variabel asli (Radiarta, Hasnawi, \& Mustafa, 2013). Tujuan utamanya ialah menjelaskan sebanyak mungkin jumlah varian data asli dengan sedikit mungkin komponen utama yang disebut faktor.

Regresi komponen utama adalah suatu analisis regresi yang digunakan untuk mengetahui hubungan antara variabel bebas dengan variabel terikat yang tak saling berkorelasi atau tidak terjadi multikolinearitas. Metode regresi komponen utama bertujuan untuk menyederhanakan variabel yang diamati dengan cara menyusutkan (mereduksi) dimensinya. Hal ini dilakukan dengan cara menghilangkan korelasi diantara variabel bebas melalui transformasi variabel bebas asal ke variabel baru yang tidak berkorelasi sama sekali.

Jurnal yang terkait Principal Componen Analisys (PCA) pernah dibahas (Nasution, 2019) untuk mengetahui faktor dominan yang mempengaruhi prestasi belajar siswa di SMK Raksana 2 Medan. Penelitian ini menggunakan metode PCA untuk mereduksi variabel-variabel yang memengaruhi prestasi belajar sehingga diperoleh tiga faktor. Penelitian ini juga memberikan hasil bahwa faktor yang dominan memengaruhi prestasi belajar siswa adalah faktor utama: bakat, motivasi, kualitas pengajaran, fasilitas sekolah, dan pergaulan. Selanjutnya faktor pendukung: ekstrakurikuler dan les tambahan, serta faktor pendukung: minat, motivasi orang tua, dan fasilitas belajar di rumah.

Tujuan dari penelitian ini adalah untuk menentukan faktor-faktor yang mempengaruhi penyelesaian skripsi mahasiswa Pendidikan Matematika Universitas Nusa Cendana. 
Penerapan Metode Principal Component Analysis (PCA) Terhadap Faktor-faktor yang Mempengaruhi Lamanya Penyelesaian Skripsi Mahasiswa Program Studi Pendidikan Matematika FKIP UNDANA, Magdalena Wangge

\section{METODE}

\section{Teknik Analisis Data}

\section{Analisis Deskripsi}

Dalam analisis deskripsi dilakukan dengan menggunakan tabel, grafik atau diagram untuk memudahkan penafsiran dalam menggambarkan tanggapan responden terhadap faktor-faktor yang mempengaruhi penyelesaian skripsi mahasiswa Jurusan Pendidikan Matematika FKIP Undana.

\section{Principal Component Analysis (PCA)}

Setelah data terkumpul maka dilakukan analisis data menggunakan Principal Component Analysis (PCA) dengan langkah-langkah sebagai berikut:

1. Menguji variabel-variabel yang telah ditentukan dengan menggunakan metode uji The Kaiser Meyer Olkin (KMO) dan Barlett test of Sphericit.

2. Uji Measure Sampling Adequency (MSA). Nilai MSA berperan untuk mengetahui besar korelasi parsial antar variabel, dilakukan dengan memperhatikan angka MSA berkisar antara 0 sampai 1 dengan kriteria sebagai berikut:

- $\mathrm{MSA}=1$, variabel tersebut dapat diprediksi untuk analisis lebih lanjut

- $\mathrm{MSA}>0,5$; variabel tersebut masih bisa diprediksi dan bisa dianalisis lebih lanjut

- $\mathrm{MSA}<0,5$; variabel tidak bisa diprediksi dan tidak bisa dianalisis lebih lanjut.

3. Melakukan proses Factoring atau menurunkan satu atau lebih faktor dari variabel-variabel yang telah diuji pada langkah kedua.

4. Pendugaan bobot faktor (factor loading) yaitu menentukan jumlah faktor yang akan terbentuk dengan melihat nilai eigen yang lebih dari satu.

5. Skor faktor, merupakan ukuran yang menyatakan representatif suatu variabel oleh masing-masing faktor, dan merupakan data mentah bagi analisis lanjutan, dapat juga dikatakan sebagai ukruan komposit untuk setiap faktor pada masing-masing objek.

6. Model faktor.

Selanjutnya didapatkan variabel bebas baru $\left(F_{1}, F_{2}, F_{3}, \ldots, F_{n}\right)$ melalui metode Principal Component Analysis (PCA) maka selanjutnya variabel bebas baru tersebut diregresikan dengan variabel tak bebas (Y). Kemudian pada tahap berikutnya, dibuatkan kesimpulan.

\section{Jenis Penelitian}

Jenis penelitian ini adalah penelitian kualitatif yang dilakukan dengan menggunakan model matematika terapan untuk menyelidiki masalah tertentu dalam menemukan solusi yang dapat diimplementasikan bagi penyelesaian masalah atau membantu membuat keputusan yang sesuai dari masalah yang dihadapi.

\section{Instrumen Penelitian}

Instrumen yang digunakan yaitu berupa angket dan sudah divalidasi. Berikut disajikan instrumen angket tersebut. 


\section{ANGKET PENELITLAN}

\section{PENGANTAR}

Berikut iri terdapat serangkaian penyataan uncuk mengetakui fabsor-faktor yang dianggap paling berpenganu

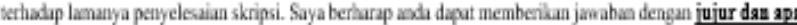

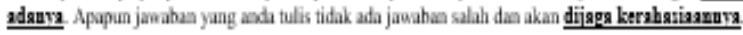

Isilah dengun cermat da bila masia ada waktu peiksalah kenbali jawahan ada. Tenina kasih atas kesodian anda mengiki alat ubur ini.

\section{IDENTTAS RESPONDEN}

Nama

Jenis Kelamia

NIM

Taluen Wisuda

Rentang waktu penyelesaiza stripsi *: ......... bulan

\section{PETUNJUK PENGISLAN}

Berilah tandz ces (V) pada kolom yang sesaai dengan jaw ahun asda, yaitu

TP : Jika anda bidak perush menasa seperti pada penyataun

P : Jika anda perzah merasa seperti pada pernyataan

KD : Jika anda kadang-kadang seperti pada pernyataas

SLL. : Jika anda selalu seperti pada pernyazam
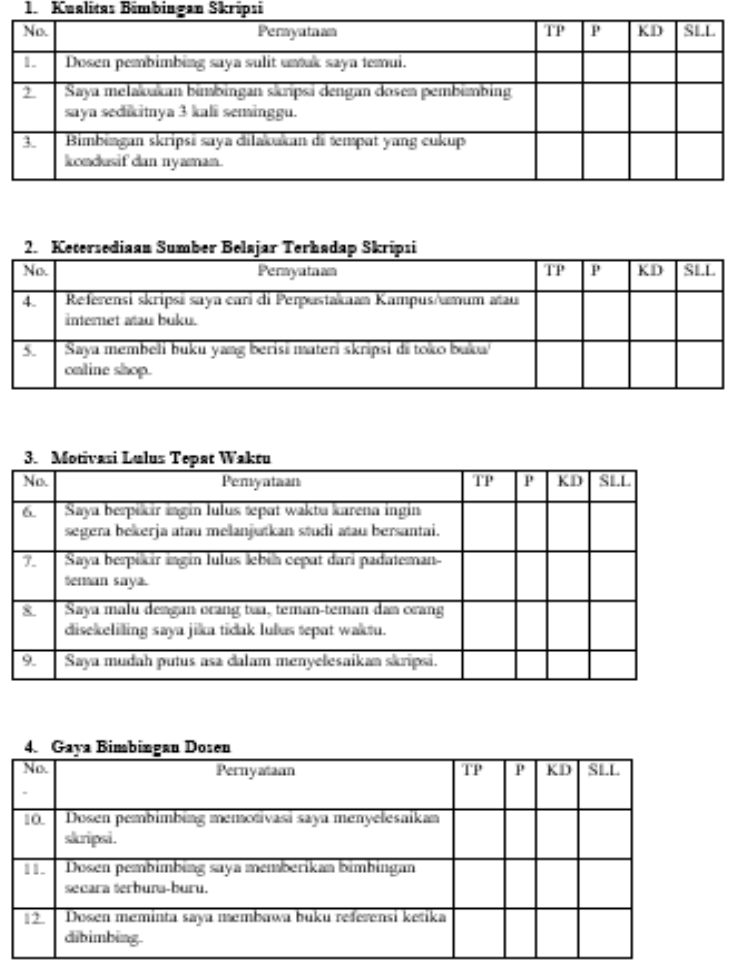

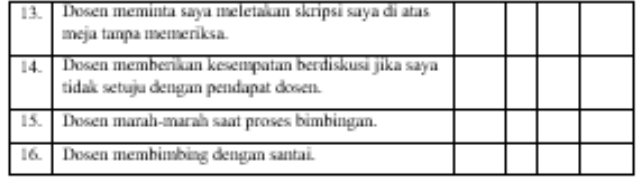

5. Sikap dan Interalei dengan Doseu Pembimbing

\begin{tabular}{|c|c|c|c|c|c|}
\hline No. & Penyatain & TP & $P$ & $\mathrm{KD}$ & SLLL \\
\hline 17. & 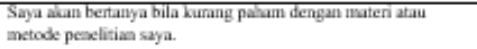 & & & & \\
\hline 18 & $\begin{array}{l}\text { Saya berusaha berkonsultasi meskipuin saya tidaik senang dengman } \\
\text { cara bimbingen dosen. }\end{array}$ & & & & \\
\hline 19. & Saya merasa akrab dan nyaman denga dosen pembimbing. & & & & \\
\hline 20 & 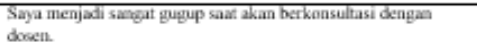 & & & & \\
\hline
\end{tabular}

\begin{tabular}{|c|c|c|c|c|c|}
\hline No. & Pernvatava & TP & p & $\mathrm{KD}$ & \\
\hline 21. & 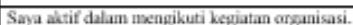 & & & & \\
\hline 22 & 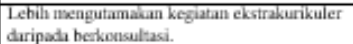 & & & & \\
\hline
\end{tabular}

\begin{tabular}{|c|c|c|c|c|c|}
\hline No. & Penyatain & TP & P & $\mathrm{KD}$ & SLL. \\
\hline 23. & $\begin{array}{l}\text { Saya merasa nyalnan ketika mengerjakan skripsi di } \\
\text { sumah' kos. }\end{array}$ & & & & \\
\hline 24. & $\begin{array}{l}\text { Lokasi tempsit tingegl dani kamper menjadi alasall } \\
\text { saya malas berhoesultasi. }\end{array}$ & & & & \\
\hline
\end{tabular}

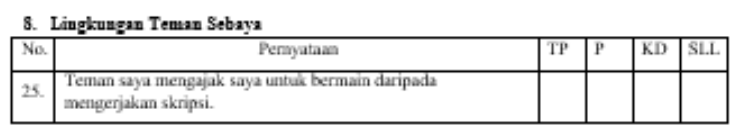

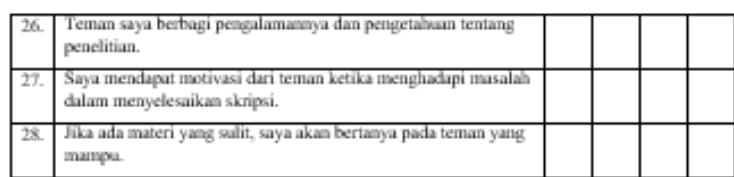

\begin{tabular}{|c|c|c|c|c|c|}
\hline No. & Penyataan & TP & P & $\mathrm{KD}$ & SLLL. \\
\hline 29. & Memkagi wakta untuk mengerjakan skripsi setiap hari. & & & & \\
\hline 30 & 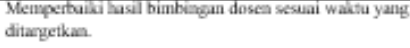 & & & & \\
\hline
\end{tabular}

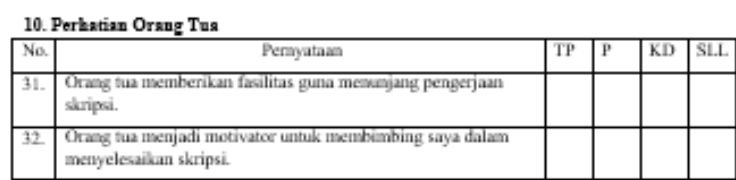

\begin{tabular}{|c|c|c|c|c|c|}
\hline \multicolumn{6}{|c|}{ 11. Kecerdasan Emosioual } \\
\hline No. & Penzyataan & $T \mathrm{TP}$ & $P$ & $\mathrm{KD}$ & SL.L \\
\hline 33. & $\begin{array}{l}\text { Saya mampu memacu semangat belajer saya meski dallam } \\
\text { poibudi saya sedang dalam masalah. }\end{array}$ & & & & \\
\hline 34. & Sava memotivasi dri sendiri untuk mencapai hasil yang tectraik. & & & & \\
\hline
\end{tabular}

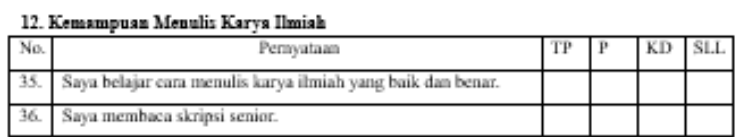

Terima kasih atas puttisipusi dat walmu yang diediabiat untak mergisi angkes ini TUHAN MEMBERKATI

Gambar 1. Instumen Angket Penelitian

\section{Populasi dan Sampel}

Populasi dalam penelitian ini adalah mahasiswa Pendidikan Matematika FKIP Universitas Nusa cendana Kupang, sedangkan sampel yang diambil untuk diteliti sebanyak 50 sampel yang dipilih secara random pada bulan Januari hingga Februari 2020. 
Penerapan Metode Principal Component Analysis (PCA) Terhadap Faktor-faktor yang Mempengaruhi Lamanya Penyelesaian Skripsi Mahasiswa Program Studi Pendidikan Matematika FKIP UNDANA, Magdalena Wangge

\section{Sumber Data}

Data yang digunakan dalam penelitian ini meliputi data primer yang diperoleh dari angket dan data sekunder berupa data lama penyelesaian skripsi mulai dari waktu penerimaan judul hingga pelaksanaan ujian skripsi.

\section{Prosedur Penelitian}

1. Melakukan identifikasi dan perumusan masalah mengenai pengaruh faktor-faktor yang berpengaruh terhadap penyelesaian skripsi mahasiswa Pendidikan Matematika.

2. Pengumpulan data dengan cara menyusun kuesioner dan menyebarkan kepada subyek penelitian.

3. Mengolah dan menganalisis data menggunakan metode Principal Component Analisys (PCA) dengan bantuan program SPSS Versi 22.

4. Membuat kesimpulan dari hasil pembahasan.

Atau disajikan dalam road map sebagai berikut.

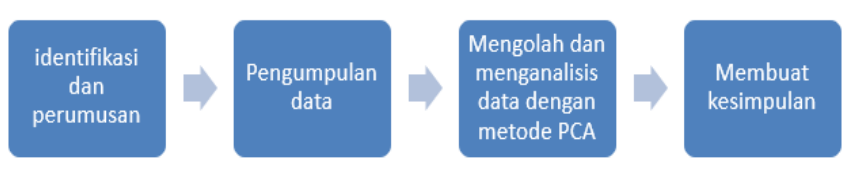

Gambar 2. Road Map penelitian

\section{Variabel Penelitian}

Variabel yang digunakan dalam penelitian ini sebanyak 14 variabel dimana terdapat 13 variabel yang dikaji dari dalam diri mahasiswa maupun dari luar yang diduga dapat mempengaruhi penyelesaian Skripsi mahasiswa yaitu: (1) Kualitas bimbingan skripsi; (2) Ketersediaan sumber belajar terhadap skripsi; (3) Motivasi lulus tepat waktu; (4) Gaya bimbingan dosen; (5) Sikap dan interaksi dengan dosen pembimbing; (6) Kegiatan kemahasiswaan; (7) Suasana tempat tinggal; (8) Lingkungan teman sebaya; (9) Membagi waktu; (10) Kesehatan; (11) Perhatian orang tua; (12) Kecerdasan emosional; dan (13) Kemampuan menulis karya ilmiah.

\section{HASIL DAN DISKUSI}

\section{Identifikasi dan Perumusan Masalah}

Berdasarkan uraian masalah yang sudah diuraikan di bagian pendahuluan, maka permasalahan yang dikaji dalam penelitian ini adalah faktor-faktor apa saja yang mempengaruhi penyelesaian skripsi mahasiswa Pendidikan Matematika Universitas Nusa Cendana.

\section{Pengumpulan Data}

Data yang dikumpulkan melalui kuesioner yang sudah diisi oleh subjek penelitian kemudian kategorikan dalam setiap variabelnya. Untuk setiap variabel, peneliti memberikan minimal 2 sampai 8 pertanyaan dimana untuk setiap pertanyaan memiliki 4 jawaban yang mempunyai skor terkecil 1 dan terbesar 4 dengan demikian untuk setiap variabel memiliki skala terkecil 2 dan skala terbesar 28. Berikut adalah tanggapan responden secara umum terhadap 12 variabel berdasarkan 6 kategori yang ditentukan 
yaitu:

Tabel 2. Tanggapan Alumni Secara Umum

\begin{tabular}{|c|c|c|c|}
\hline No & Variabel & $\begin{array}{c}\text { Tanggapan } \\
\text { Responden }\end{array}$ & Kategori \\
\hline 1 & Kualitas bimbingan skripsi & 2,84 & Agak baik \\
\hline 2 & Ketersediaan sumber belajar terhadap skripsi & 2,74 & Agak baik \\
\hline 3 & Motivasi lulus tepat waktu & 2,79 & Agak baik \\
\hline 4 & Gaya bimbingan dosen & 2,32 & Lebih dari cukup baik \\
\hline 5 & Sikap dan interaksi dengan dosen pembimbing & 2,91 & Agak baik \\
\hline 6 & Kegiatan kemahasiswaan & 1,88 & Cukup baik \\
\hline 7 & Suasana tempat tinggal & 2,80 & Agak baik \\
\hline 8 & Lingkungan teman sebaya & 3 & Baik \\
\hline 9 & Membagi waktu & 3,38 & Baik \\
\hline 10 & Perhatian orang tua & 3,79 & Sangat baik \\
\hline 11 & Kecerdasan emosional & 3,23 & Baik \\
\hline 12 & Kemampuan menulis karya ilmiah & 3,17 & Baik \\
\hline
\end{tabular}

Keterangan:

$$
\begin{aligned}
& 3,5-4,0=\text { sangat baik } \\
& 3,0-3,4=\text { baik } \\
& 2,5-2,9=\text { agak baik } \\
& 2,0-2,4=\text { lebih dari cukup baik } \\
& 1,5-1,9=\text { cukup baik } \\
& 1,0-1,4=\text { tidak baik }
\end{aligned}
$$

Tabel 2 menunjukan bahwa tanggapan mahasiswa secara umum terhadap 13 variabel dimana variabel yang dikategorikan sangat baik yaitu Perhatian orang tua sehingga terlihat bahwa mahasiswa mendapat dukungan yang banyak dalam proses mengerjakan skripsi. Variabel yang dikategorikan baik adalah lingkungan teman sebaya, cara membagi waktu, kecerdasan emosional dan kemampuan dalam menulis karya ilmiah. Variabel yang dikategorikan agak baik adalah, suasana tempat tinggal, kualitas bimbingan skripsi, ketersediaan sumber belajar terhadap skripsi, motivasi lulus tepat waktu, sikap dan interaksi dengan dosen pembimbing. Variabel yang dikategorikan lebih dari cukup baik adalah gaya bimbingan dosen. Variabel yang dikategorikan cukup baik adalah kegiatan kemahasiswaan.

\section{Perhitungan Principal Component Analysis (PCA)}

Tahap pertama pada metode Principal Component Analysis adalah menilai variabel mana saja yang dianggap layak untuk dimasukan dalam analisis selanjutnya. Pengujian ini dilakukan dengan memasukan semua variabel yang ada, kemudian pada variabel-varibel dikenakan sejumlah pengujian. Jika sebuah variabel memang mempunyai kecenderungan mengelompok dan membentuk sebuah faktor, maka variabel tersebut akan mempunyai korelasi yang cukup tinggi dengan varibel lainnya. Sebaliknya, variabel dengan korelasi yang lemah dengan variabel lain cenderung tidak akan mengelompok dalam faktor tertentu.

Dengan menggunakan aplikasi SPSS, Principal Component Analysis (PCA) dimulai dengan uji Bartlett, uji Kaiser Meiyer Olkin (KMO) dan Measures of Adequancy (MSA). 
Penerapan Metode Principal Component Analysis (PCA) Terhadap Faktor-faktor yang Mempengaruhi Lamanya Penyelesaian Skripsi Mahasiswa Program Studi Pendidikan Matematika FKIP UNDANA, Magdalena Wangge

\section{Uji Bartlett}

Adapun hipotesis yang dibentuk dalam pengujian ini adalah sebagai berikut:

$H_{0}=$ tidak ada korelasi antar variabel bebas

$H_{1}=$ ada korelasi antar variabel bebas

Berdasarkan perhitungan dengan menggunakan SPSS diperoleh:

Tabel 3. Hasil Uji KMO dan Bartlett

\begin{tabular}{|c|c|c|}
\hline \multicolumn{2}{|c|}{ Kaiser-Meyer-Olkin Measure of Sampling Adequacy. } & .648 \\
\hline \multirow[t]{3}{*}{ Bartlett's Test of Sphericity } & Approx. Chi-Square & 140.646 \\
\hline & $d f$ & 66 \\
\hline & Sig. & .000 \\
\hline
\end{tabular}

Dari tabel di atas menunjukkan bahwa sig. yaitu $0,000<0,05$, maka $H_{0}$ ditolak. Artinya terdapat korelasi antar variabel bebas.

\section{Uji Kaiser Mayer Olkin (KMO)}

Berdasarkan perhitungan dengan menggunakan SPSS diperoleh: $\mathrm{KMO}=0,648$ artinya kecukupan sampling tersebut dapat diterima karena lebih besar dari 0,5 sehingga analisis PCA dapat dilanjutkan atau layak digunakan.

\section{Uji Measure of Sampling Adequacy (MSA)}

Berdasarkan perhitungan menggunakan SPSS, maka nilai MSA untuk masing-masing variabel secara ringkas dapat dilihat pada tabel berikut:

Tabel 4. Nilai MSA untuk 12 Variabel

\begin{tabular}{|c|c|c|}
\hline No & Variabel & Nilai MSA \\
\hline 1 & Kualitas bimbingan skripsi & 0,763 \\
\hline 2 & Ketersediaan sumber belajar terhadap skripsi & 0,601 \\
\hline 3 & Motivasi lulus tepat waktu & 0,541 \\
\hline 4 & Gaya bimbingan dosen & 0,835 \\
\hline 5 & Sikap dan interaksi dengan dosen pembimbing & 0,710 \\
\hline 6 & Kegiatan kemahasiswaan & 0,593 \\
\hline 7 & Suasana tempat tinggal & $\mathbf{0 , 4 9 7}$ \\
\hline 8 & Lingkungan teman sebaya & 0,669 \\
\hline 9 & Membagi waktu & 0,771 \\
\hline 10 & Perhatian orang tua & 0,627 \\
\hline 11 & Kecerdasan emosional & $\mathbf{0 , 4 8 7}$ \\
\hline 12 & Kemampuan menulis karya ilmiah & 0,664 \\
\hline
\end{tabular}

Berdasarkan kriteria angka MSA, pada tabel di atas terlihat bahwa ada angka MSA memiliki nilai di bawah 0,5 yaitu variabel suasana tempat tinggal dan kecerdasan emosional sehingga data diuji ulang. Hasil dari proses perhitungan ulang yang dilakukan dengan tidak mengikutsertakan variabel suasana tempat tinggal dan kecerdasan emosional adalah: 


\section{Uji Bartlett}

Berdasarkan perhitungan dengan menggunakan SPSS diperoleh:

Tabel 5. Hasil Uji KMO dan Bartlett untuk 10 variabel

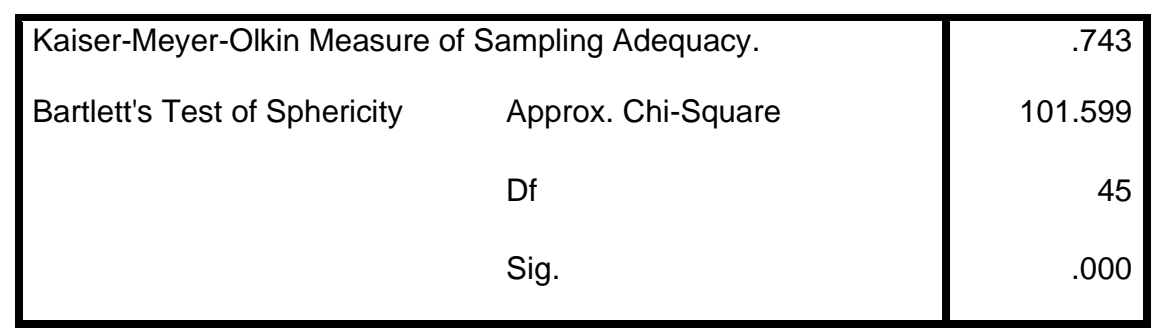

Dari tabel di atas menunjukkan bahwa sig. yaitu $0,000<0,05$, maka $H_{0}$ ditolak. Artinya terdapat korelasi antar variabel bebas.

\section{Uji Kaiser Mayer Olkin (KMO)}

Berdasarkan perhitungan dengan menggunakan SPSS diperoleh: $\mathrm{KMO}=0,743$ artinya kecukupan sampling tersebut dapat diterima karena lebih besar dari 0,5 sehingga analisis PCA dapat dilanjutkan atau layak digunakan.

\section{Uji Measure of Sampling Adequacy (MSA)}

Berdasarkan perhitungan menggunakan SPSS, maka nilai MSA untuk masing-masing variabel secara ringkas dapat dilihat pada tabel berikut:

Tabel 6. Nilai MSA untuk 10 Variabel

\begin{tabular}{|c|c|c|}
\hline No & Variabel & Nilai MSA \\
\hline 1 & Kualitas bimbingan skripsi & 0,808 \\
\hline 2 & Ketersediaan sumber belajar terhadap skripsi & 0,830 \\
\hline 3 & Motivasi lulus tepat waktu & 0,656 \\
\hline 4 & Gaya bimbingan dosen & 0,833 \\
\hline 5 & Sikap dan interaksi dengan dosen pembimbing & 0,749 \\
\hline 6 & Kegiatan kemahasiswaan & 0,735 \\
\hline 7 & Lingkungan teman sebaya & 0,669 \\
\hline 8 & Membagi waktu & 0,717 \\
\hline 9 & Perhatian orang tua & 0,725 \\
\hline 10 & Kemampuan menulis karya ilmiah & 0,756 \\
\hline
\end{tabular}

Setelah mereduksi variabel yang memiliki nilai MSA yang kurang dari 0,5 dan tidak lagi ditemukan lagi variabel dengan nilai MSA dibawah dari 0,5. Pada tabel 6 terlihat bahwa angka MSA untuk setiap variabel terjadi peningkatan dari sebelumnya, hal ini berarti setiap pengulangan proses dengan dikeluarkan variabel yang mempunyai MSA di bawah 0,5 akan menaikan nilai MSA 
Penerapan Metode Principal Component Analysis (PCA) Terhadap Faktor-faktor yang Mempengaruhi Lamanya Penyelesaian Skripsi Mahasiswa Program Studi Pendidikan Matematika FKIP UNDANA, Magdalena Wangge

keseluruhan.

\section{Communalities}

Communalities menunjukkan berapa varians yang dapat dijelaskan oleh faktor yang terbentuk. Berikut tabel hasil perhitungannya:

Tabel 7. Communalities

\begin{tabular}{|c|c|}
\hline Variabel & Extraction \\
\hline Kualitas bimbingan skripsi & 0,656 \\
\hline Ketersediaan sumber belajar terhadap skripsi & 0,388 \\
\hline Motivasi lulus tepat waktu & 0,765 \\
\hline Gaya bimbingan dosen & 0,576 \\
\hline Sikap dan interaksi dengan dosen pembimbing & 0,720 \\
\hline Kegiatan kemahasiswaan & 0,680 \\
\hline Lingkungan teman sebaya & 0,773 \\
\hline Membagi waktu & 0,719 \\
\hline Perhatian orang tua & 0,687 \\
\hline Kemampuan menulis karya ilmiah & 0,690 \\
\hline
\end{tabular}

Dari tabel di atas terlihat pada variabel $\mathrm{x}_{1}$, diperoleh nilai sebesar $0,656=65 \%$. Hal ini berarti $65 \%$ variabel $\mathrm{x}_{1}$ dapat dijelaskan oleh faktor yang terbentuk. Demikian juga untuk variabel $\mathrm{x}_{2}$ sampai $\mathrm{X}_{13}$.

\section{Factoring}

Kriteria penentuan jumlah faktor yang akan terbentuk dapat dilihat dari komponen yang memiliki nilai eigen lebih besar dari pada 1. Dari hasil analisis diperoleh nilai-nilai eigen seperti pada tabel dibawah ini.

Tabel 8. Nilai-nilai eigen

\begin{tabular}{|c|c|c|c|}
\hline Komponen & Eigen & \%Varians & \% Kumulatif \\
\hline 1 & $\mathbf{3 , 3 0 0}$ & $\mathbf{3 2 , 9 9 6}$ & $\mathbf{3 2 , 9 9 6}$ \\
\hline 2 & $\mathbf{1 , 2 5 0}$ & $\mathbf{1 2 , 5 0 4}$ & $\mathbf{4 5 , 5 0 0}$ \\
\hline 3 & $\mathbf{1 , 0 9 7}$ & $\mathbf{1 0 , 9 7 2}$ & $\mathbf{5 6 , 4 7 3}$ \\
\hline 4 & $\mathbf{1 , 0 0 6}$ & $\mathbf{1 0 , 0 6 2}$ & $\mathbf{6 6 , 5 3 5}$ \\
\hline 5 & 0,824 & 8,238 & 74,772 \\
\hline 6 & 0,673 & 6,726 & 81,499 \\
\hline 7 & 0,581 & 5,812 & 87,311 \\
\hline 8 & 0,550 & 5,496 & 92,807 \\
\hline 9 & 0,386 & 3,864 & 96,671 \\
\hline 10 & 0,333 & 3,329 & 100,000 \\
\hline
\end{tabular}

Pada tabel di atas, keempat faktor dengan nilai eigen lebih besar dari 1 memberikan proporsi keragaman kumulatif sebesar 66,535\% yang berarti bahwa keempat faktor tersebut mampu menyerap informasi dalam data sebesar $66,535 \%$. Untuk melihat variabel-variabel yang masuk ke dalam setiap faktor yang 
terbentuk terlebih dahulu dicari faktor loading yang menunjukan besarnya korelasi antara suatu variabel dengan faktor yang terbentuk.

Tabel 9. Komponen Matriks

\begin{tabular}{|c|c|c|c|c|}
\hline \multirow{2}{*}{ Variabel } & \multicolumn{4}{|c|}{ Komponen } \\
\hline & 1 & 2 & 3 & 4 \\
\hline $\mathrm{X} 1$ & .608 & -.129 & -.074 & .514 \\
\hline $\mathrm{X} 2$ & .437 & .392 & .182 & .100 \\
\hline $\mathrm{X} 3$ & .493 & -.612 & .378 & -.071 \\
\hline $\mathrm{X} 4$ & .718 & .122 & .146 & .159 \\
\hline $\mathrm{X} 5$ & .695 & .272 & .053 & -.400 \\
\hline $\mathrm{X} 6$ & .397 & .420 & .399 & .432 \\
\hline $\mathrm{X} 7$ & .637 & -.572 & .161 & -.121 \\
\hline $\mathrm{X} 8$ & .532 & .065 & -.653 & .071 \\
\hline X9 & .641 & -.095 & -.517 & -.008 \\
\hline $\mathrm{X} 10$ & .492 & .316 & .114 & -.579 \\
\hline
\end{tabular}

Tabel di atas menunjukan distribusi ke-14 variabel pada empat faktor yang terbentuk. Proses penentuan variabel mana yang akan masuk ke faktor dengan melakukan perbandingan besar korelasi setiap baris. Untuk lebih ringkas pengelompokan variabel dalam faktor ditampilkan dalam tabel di bawah ini.

Tabel 10. Pengelompokan Variabel dalam Faktor

\begin{tabular}{|c|c|c|}
\hline Faktor & Loading & Variabel \\
\hline \multirow{4}{*}{1} & 0,608 & Kualitas bimbingan skripsi \\
\cline { 2 - 3 } & 0,437 & Ketersediaan sumber belajar \\
\cline { 2 - 3 } & 0,718 & Gaya bimbingan dosen \\
\cline { 2 - 3 } & 0,695 & Sikap dan interaksi dengan dosen pembimbing \\
\cline { 2 - 3 } & 0,637 & Lingkungan teman sebaya \\
\cline { 2 - 3 } & 0,641 & Perhatian orang tua \\
\hline 2 & $-0,612$ & Motivasi lulus tepat waktu \\
\hline 3 & $-0,653$ & Membagi waktu \\
\hline \multirow{2}{*}{4} & 0,432 & Kegiatan kemahasiswaan \\
\cline { 2 - 3 } & $-0,579$ & Kemampuan menulis karya ilmiah \\
\hline
\end{tabular}

\section{Pemodelan}

Faktor - faktor yang telah diperoleh melalui metode Principal Component Analysis akan di analisis lebih lanjut dengan menggunakan metode analisis regrresi berganda untuk mendapatkan model. Hasil perhitungan menggunakan spss ditunjukan sebagai berikut:

Tabel 11. Coefficients

\begin{tabular}{|c|c|c|c|c|c|}
\hline \multirow{3}{*}{ Model } & \multicolumn{2}{|c|}{$\begin{array}{c}\text { Unstandardized } \\
\text { Coefficients }\end{array}$} & $\begin{array}{c}\text { Standardized } \\
\text { Coefficients }\end{array}$ & & \\
\cline { 2 - 4 } & $\mathrm{B}$ & Std. Error & Beta & $\mathrm{t}$ & Sig. \\
\cline { 2 - 6 }
\end{tabular}


Penerapan Metode Principal Component Analysis (PCA) Terhadap Faktor-faktor yang Mempengaruhi Lamanya Penyelesaian Skripsi Mahasiswa Program Studi Pendidikan Matematika FKIP UNDANA, Magdalena Wangge

\begin{tabular}{|c|c|c|c|c|c|}
\hline (Constant) & 2,943 &, 036 & & 81,137 &, 000 \\
Faktor_1 &, 028 &, 036 &, 024 &, 222 &, 025 \\
Faktor_2 &, 064 &, 036 &, 230 & 2,057 &, 235 \\
Faktor_3 &, 120 &, 036 & .276 & $-2,763$ &, 009 \\
Faktor_4 &, 089 &, 036 &, 288 & 2,672 &, 027 \\
\hline
\end{tabular}

Dengan demikian model regresi komponen utama yang didapat adalah:

$$
I P K=2,943+0,028 F 1+0,064 F 2+0,120 F 3+0,089 F 4
$$

\section{Pembahasan}

Analisis komponen utama (Principal Component Analysis) merupakan analisis untuk memperkecil dimensi data tanpa kehilangan banyak informasi dengan cara mengubah (mentransformasi) suatu matriks data awal/asli menjadi suatu set komponen utama yang menyerap sebagian besar jumlah varian data awal. Tujuan utamanya ialah menjelaskan sebanyak mungkin varian data awal dengan sedikit komponen utama yang disebut faktor. Dimana faktor yang terbentuk ini merupakan kombinasi linear dari variabel yang diteliti dan mampu menerangkan keberagaman data secara maksimal sehingga mempermudah peneliti dalam menganalisis.

Terdapat salah satu penelitian oleh Kurniawan (Kurniawan, 2008) yang menggunakan metode Principal Component Analysis dalam penentuan faktor penilaian kinerja pengajar. Dalam penelitiannya, Wawan menggunakan metode ini utnuk mereduksi 11 variabel yang berkorelasi hingga menjadi 3 faktor baru yang tidak terdapat korelasi atau multikolinearitas.

Pada penelitian kali ini peneliti juga menggunakan metode yang sama yaitu metode Principal Component Analysis terhadap faktor-faktor yang memengaruhi penyelesaian skripsi. Penelitian ini memperoleh 4 komponen utama yang menjadi faktor dari 12 variabel yang diteliti.

Principal component analysis tidak dapat dilakukan jika tidak terdapat korelasi atau multikolinearitas diantara variabel-variabel yang diteliti sehingga terlebih dahulu dilakukan beberapa pengujian. Setelah melalui semua tahapan pengujian, diperoleh model faktor:

$$
I P K=2,943+0,028 F 1+0,064 F 2+0,120 F 3+0,089 F 4
$$

dengan $R^{2}=22,8 \%$.

Dari model diatas menunjukan bahwa kemampuan keempat faktor dalam menjelaskan varians proses penyelesaian skripsi mahasiswa sebesar 22,78 \% dan sisanya dijelaskan oleh faktor lain yang tidak dimasukan dalam vmodel dan kemudian yang menjadi faktor dominan dalam mempengaruhi penyelesaian skripsi adalah faktor ke 3 dimana faktor tersebut adalah faktor membagi waktu. Sehingga interpretasi terhadap faktor ini adalah jika mahasiswa membagi waktu dengan meningkat 1 satuan maka proses penyelesaian skripsi akan meningkat sebesar 0,120.

Implementasi terhadap variabel-variabel pada penelitian ini yaitu secara teori memiliki hubungan dengan penyelesaian skripsi mahasiswa namun dalam analisis dengan menggunakan kedua metode ini 
yaitu PCA dan analisis regresi komponen utama menunjukan bahwa dalam Populasi mahasiswa prodi pendidikan Matematika hanya sebagian faktor pendukung penulisan skripsi, membagi waktu dan keterampilan menulis.

Dari setiap faktor yang mempengaruhi lama waktu penyelesaian skripsi, akan ada pengaruh baik maupun sebaliknya. Oleh karena itu untuk meminimalisir pengaruh yang kurang baik dapat dilakukan beberapa tindakan sebagai berikut. (1) Memilih topik dan segera mencari referensi agar tidak berpengaruh buruk pada faktor ketersediaan sumber belajar atau kurangnya informasi. Memperkirakan kerangka penelitian. Waktu yang digunakan bisa saat masa perkuliahan seperti biasa atau saat semester awal. (2) Konsultasi dengan dosen. (3) Faktor pertama yaitu faktor pendukung penulisan kualitas bimbingan skripsi, ketersediaan sumber belajar, gaya bimbingan dosen, sikap dan interaksi dengan dosen pembimbing, lingkungan teman sebaya, dan perhatian orang tua. (4) Faktor kedua yaitu faktor motivasi lulus tepat waktu. (5) Faktor ketiga yaitu faktor Membagi waktu. (6) Faktor keempat yaitu faktor keterampilan menulis. (7) Yang terakhir namun merupakan hal Pertama yang harus dilakukan adalah Berdoa agar semua hal yang dimulai atau direncanakan boleh berjalan dengan baik.

\section{KESIMPULAN}

Faktor-faktor yang mempengaruhi penyelesaian skripsi mahasiswa Pendidikan Matematika Universitas Nusa Cendana terdiri dari 4 faktor, dimana faktor 1 berkaitan dengan kualitas bimbingan skripsi, ketersediaan sumber belajar, gaya bimbingan dosen, sikap dan interaksi dengan dosen pembimbing, lingkungan teman sebaya, serta perhatian orang tua. Faktor 2 berkaitan dengan motivasi lulus tepat waktu, faktor 3 yaitu membagi waktu, serta faktor 4 terkait kegiatan kemahasiswaan dan kemampuan menulis karya ilmiah.

\section{REFERENSI}

Adelina, S. (2018). Faktor Penyebab Lamanya Mahasiswa Menyelesaikan Skripsi Di Fakultas Ekonomi Universitas Negeri Padang. Jurnal Ecogen, 1(4), 184. https://doi.org/10.24036/jmpe.v1i1.4738

Annisa, S. W. (2012). Studi keterlambatan penyelesaian skripsi mahasiswa program studi pendidikan tata rias dan kecantikan jurusan tata rias dan kecantikan fakultas pariwisata dan perhotelan. 124.

http://repositorio.unan.edu.ni/2986/1/5624.pdf\%0Ahttp://fiskal.kemenkeu.go.id/ejournal\%0Ahttp ://dx.doi.org/10.1016/j.cirp.2016.06.001\%0Ahttp://dx.doi.org/10.1016/j.powtec.2016.12.055\%0 Ahttps://doi.org/10.1016/j.ijfatigue.2019.02.006\%0Ahttps://doi.org/10.1

Broto, H. D. F. C. (2016). STRES PADA MAHASISWA PENULIS SKRIPSI (Studi Kasus pada Salah Satu Mahasiswa Program Studi Bimbingan dan Konseling Universitas Sanata Dharma). In Skripsi. Disusun oleh: Henricus Dimas Frandi Cahyo Broto NIM : 091114024 PROGRAM STUDI BIMBINGAN DAN KONSELING JURUSAN ILMU PENDIDIKAN FAKULTAS KEGURUAN DAN ILMU PENDIDIKAN UNIVERSITAS SANATA DHARMA. 
Penerapan Metode Principal Component Analysis (PCA) Terhadap Faktor-faktor yang Mempengaruhi Lamanya Penyelesaian Skripsi Mahasiswa Program Studi Pendidikan Matematika FKIP UNDANA, Magdalena Wangge 987

Elfira, F. (2014). Penerapan Analisis Faktor dalam Menentukan Faktor-faktor yang Mempengaruhi Mahasiswa dalam Memilih Jurusan Matematika Fakultas Sains dan Teknologi Universitas Islam Negeri Alauddin Makassar. Msa, 3(1), 29-36.

Fitrianingsiha, \& Sugiyartob. (2018). Implementasi analisa komponen utama untuk mereduksi variabel yang mempengaruhi perbaikan pada fungsi ginjal tikus. 8(2), 115-124.

Hadi, R. (2015). Studi Penggunaan Metode Penelitian Kuantitatif Dan Analisis Statistika Pada Skripsi Mahasiswa Iain Purwokerto. Jurnal Penelitian Agama, 16(2), 327-348. https://doi.org/10.24090/jpa.v16i2.2015.pp327-348

Hadiono, A. (2012). Analisis Faktor Penghambat Penyelesaian Skripsi Mahasiswa STIA Banten. Psychology Applied to Work: An Introduction to Industrial and Organizational Psychology, Tenth Edition Paul, 53(9), 1689-1699.

Hariyadi, S., Haris, A., Anto, F., \& Sari, W. A. (2017). Identifikasi Faktor-Faktor Yang Mempengaruhi Penyelesaian Skripsi Pada Mahasiswa S1 Psikologi Di Kota Semarang. Jurnal Penelitian Pendidikan, 34(2), 155-160. https://doi.org/10.15294/jpp.v34i2.11752

Hartato, U., \& Aisyah, M. N. (2011). Faktor-Faktor Yang Mempengaruhi Penyelesaian Skripsi Mahasiswa Pendidikan Akuntansi Universitas Negeri Yogyakarta. Prosiding Seminar Nasional: Penguatan Hubungan Antara Pengembangan Keterampilan, Pendidikan, Dan Ketenagakerjaan Generasi Muda, Universita, 131-139.

Hermawan, H. (2019). Riset Hospitalitas Metode Kuantitatif untuk Riset Bidang Kepariwisataan. https://doi.org/10.31227/osf.io/fenzh

Juaeni, I. (2014). Dampak Penerapan Principal Component Analysis ( Pca ) Dalam Clustering Curah Hujan Di Pulau Jawa, Bali, Dan Lombok [ Impact of Principal Component Analysis ( Pca ) Implementation on Rainfall Clustering Over Java, Bali and Lombok Islands ]. Jurnal Sains Dirgantara, 11, 97-108.

Kurniati, D. (2010). Analisis Faktor Penyelesaian Skripsi Mahasiswa Prodi Pendidikan Ekonomi PPAPK.

Kurniawan, W. (2008). Aplikasi Metode Principal Component Dalam Penentuan Faktor Penilaian Penilaian Kinerja Pengajar. In UIN Syarif Hidayatullah.

Kustian, N. (2016). Principal Component Analysis untuk Sistem Pengenalan Wajah dengan Menggunakan Metode Eigenface. STRING (Satuan Tulisan Riset Dan Inovasi Teknologi), 1(2), 193. https://doi.org/10.30998/string.v1i2.1042

Mariana. (2013). Analisis Komponen Utama. Jurnal Matematika Dan Pembelajarannya, 2(2), 99-114. Maulana, I. (2018). Penggunaan Metode Principal Component Analysis ( PCA ) untuk Mereduksi Faktor Faktor yang Memengaruhi Penyakit Jantung Koroner di RSUP H . Adam Malik Medan Tahun 2017.

Nasution, M. Z. (2019). PENERAPAN PRINCIPAL COMPONENT ANALYSIS (PCA) DALAM PENENTUAN FAKTOR DOMINAN YANG MEMPENGARUHI PRESTASI BELAJAR 
SISWA (Studi Kasus: SMK Raksana 2 Medan). Jurnal Teknologi Informasi, 3(1), 41. https://doi.org/10.36294/jurti.v3i1.686

Noya van Delsen, M. S., Wattimena, A. Z., \& Saputri, S. (2017). Penggunaan Metode Analisis Komponen Utama Untuk Mereduksi Faktor-Faktor Inflasi Di Kota Ambon. BAREKENG: Jurnal Ilmu Matematika Dan Terapan, 11(2), 109-118. https://doi.org/10.30598/barekengvol11iss2pp109-118

Pratiwi, D. E., \& Roosyanti, A. (2019). Analisis Faktor Penghambat Skripsi Mahasiswa Jurusan Pendidikan Guru Sekolah Dasar Universitas Wijaya Kusuma Surabaya. Jurnal Pendidikan Dasar, 10(1), 101-114.

Qomari, R. (1970). Teknik Penelusuran Analisis Data Kuantitatif dalam Penelitian Kependidikan. INSANIA: Jurnal Pemikiran Alternatif Kependidikan, 14(3), 527-539. https://doi.org/10.24090/insania.v14i3.372

Radiarta, I Nyoman, Hasnawi, dan A. M. (2013). Kondisi Kualitas Perairan Di Kabupaten Morowali Provinsi Sulawesi Tengah: June 2011, 299-309.

Rismen, S. (2015). Analisis kesulitan mahasiswa dalam penyelesaian skripsi di Prodi Pendidikan Matematika STKIP PGRI. Lemma, I(2), 57-62. ejournal.stkip-pgri-sumbar.ac.id/index.php/jurnallemma/article/view/538

Saepurohman, T., \& Putro, B. E. (2019). Analisis Principal Component Analysis (PCA) Untuk Mereduksi Faktor-Faktor yang Mempengaruhi Kualitas Kulit Kikil Sapi. Prosiding Seminar \& Konferensi Nasional IDEC, 2008, C01.1-C01.10. https://idec.ft.uns.ac.id/prosiding2019

Sulasteri, S. R. I., Nur, F., \& Kusumayanti, A. (2019). Faktor-faktor penyebab keterlambatan mahasiswa uin alauddin makassar menyelesaikan skripsi. III(1), 96-113.

Syakhala, A. R., Puspitaningrum, D., \& Purwandari, E. P. (2015). Perbandingan Metode Principal Component Analysis (PCA) dengan Metode Hidden Markov Model (HMM) dalam Pengenalan Identitas. Jurnal Informatika, 3(2), 68-81. https://ejournal.unib.ac.id/index.php/rekursif/issue/archive

Wirayanti, Setiawan, A., \& Susanto, B. (2014). Studi Simulasi Tentang Penerapan Grafik Pengendali Berdasarkan Analisis Komponen Utama (Principal Component Analysis). November, 15-25.

Zein, S., Yasyifa, L., Ghozi, R., Harahap, E., Badruzzaman, F., \& Darmawan, D. (2019). Pengolahan dan Analisis Data Kuantitatif Menggunakan Aplikasi SPSS. Jurnal Teknologi Pendidikan Dan Pembelajaran, 4(1), 1-7. 